\title{
1. Introduction: can we make American democracy work?
}

\author{
Melody C. Barnes, Corey D.B. Walker and \\ Thad M. Williamson
}

Historic levels of economic inequality. Deep partisan divides. Rising levels of intolerance and hate-fueled acts of violence. What started as an audacious experiment in political community now appears to be in crisis. And the current crisis is not a short-term one that can be "fixed" at the next election. Rather, the current crisis is historic and existential and calls into question the very legitimacy and future of American democracy. In many ways, American democracy stands in the wake of the probing question raised by Dr. Martin Luther King, Jr., "Where do we go from here?" (King, 1967).

Americans are frustrated by the inability of democracy to deliver. Viable and sustainable solutions to the litany of problems plaguing society seem to elude politicians, public officials, scholars, and citizens. To be sure, a healthy degree of frustration with the processes and outcomes of democratic institutions is not a defect but an essential institutional feature of democratic systems. However, in a democratic system of majority rule, democracy may succumb to what Alexis de Tocqueville termed "its prejudices and its passions" (Tocqueville, 1835 [2004], p. 15). A frustrated minority structurally out of power and a frustrated majority that holds power- each unable to fully respond to the real and felt needs of their respective constituency_precipitates a profound crisis.

While some aspects of the present political moment indeed take the familiar form of "normal" democratic politics, the election and the subsequent presidency of Donald J. Trump raises more fundamental questions about not only the present state of American democratic institutions but also the deeper flaws in the historic architecture of those institutions. Indeed, the election and presidency of Donald Trump have thrown new light on long-standing democratic deficits in the American republic - from the archaic Electoral College to the racial wealth gap to inequalities of political voice and influence. Thus, the election of Trump can be understood as the culmination of long-standing tendencies within American democracy and its inability to effectively respond to the demands of many of its citizens over a prolonged period of time. 
Any political system that fails to deliver economic prosperity, expanded opportunity, effective problem-solving, and redress of historic injustices will lose legitimacy. America exhibits a unique inability to respond to centuries of chattel slavery and state-sanctioned racial discrimination. For nearly half a century, economic inequality in the U.S. has been widening, with incomes and social mobility stagnant for much of the population and the top 1 percent capturing the largest share of gains from economic growth. At the same time, a wide range of problems - from local public education to affordable housing to global climate change-simply have not been adequately addressed by policy-makers. Perceptions that the "system" is rigged in favor of special interests and the wealthy have risen along with distrust of public institutions and elected officials. Consequently, many millions of Americans are deeply dissatisfied with democracy and skeptical about the future.

Yet, America's democratic challenges are grounded in deeper structural issues:

- The fact that the U.S. is both an extremely diverse society and a nation with a history largely defined by white supremacy, chattel slavery, and state-sanctioned discrimination, and is largely defined by the historic and ongoing struggles to challenge structural racism in law, culture, and daily life. The exclusionary basis of the aspirations of the founding generation of American democracy and the history and present practice of America's racial democracy continue to expose the racialist and racist nature of disparities in well-being, health, income, and education that are constitutive of the U.S.

- The fact that U.S. democracy aspires to operate on a national scale while privileging localized decision-making through local and state governments. Part of American political history - and its future - involves the ongoing negotiation and rebalancing of federalism as a political arrangement; and part of American political and cultural history involves working through what it means to be a pluralist society marked by racial and ethnic diversity as well as profound regional, religious, and cultural differences.

- The fact that the U.S. has a consequential role in world affairs, variously described as either "global leadership" or "imperialist," characterized in part by the maintenance of an extraordinarily large military and near-continuous military conflicts over the past 20 years in the Middle East. The permanent "imperial presidency" is arguably both the consequence and cause of this fact, meaning that the presidency (understandably) occupies an outsized role in the American political system.

These structural issues expose the gap between our democratic aspirations and our current reality. In a moment of democratic disappointment and political 
anxiety, America comes perilously close to a legitimacy crisis. Such a crisis is distinguished by these characteristics:

- failure to develop a consensus and appropriate redress to the deeply racist and unjust legacy of its founding and subsequent history;

- failure to adequately address the economic needs of a substantial percentage of residents while inequalities of income, wealth, upward mobility, and political influence have expanded;

- failure to adequately address urgent long-standing and emergent problems, such as quality public education, equitable economic development, and ecological sustainability;

- declining faith in democracy as an institution and mode of governance and in democratic citizenship as an effective vehicle for self-rule and political community.

While it is plausible to portray these failures as a failure of political leadership, we believe there is a deeper, structural crisis afflicting American democracy. Indeed, it is not simply that political leaders have disappointed. It is that there is a lack of a compelling and coherent paradigm for addressing the most urgent, overlapping, and systemic challenges confronting American democracy in the 21 st century.

Over the past half-century, political debate has been framed as a simplistic, left vs right dichotomy over the role and size of the federal government and the degree to which it should be used as a vehicle for promoting equity and progressive social change. In this configuration, liberal politics in the U.S. has been understood as an extension, restoration, or rejuvenation of the New Deal policy paradigm: bold action by the federal government to regulate capitalism, support social programs, redistribute resources, and provide a "safety net" for all citizens. Conservative politics aims at limiting, containing, and ultimately rolling back government's role in the interests of promoting liberty, free enterprise, and social policies that reinforce normative ideals of the family. With the ascendency of a dominant conservativism, democratic politics has been characterized by strengthening parts of government - such as the militaryindustrial complex, the prison-industrial complex, and numerous specific rules and regulations favoring politically connected corporate interests - while weakening government's regulatory and redistributive roles.

Certainly, any plausible or attractive vision for American democracy in the 21 st century must go beyond a strong conservatism and a chastened liberalism. It is increasingly clear that the substantive limitations of the New Deal leave it wanting as a compelling 21 st-century paradigm for democratic renewal. Equally important, returning to a New Deal vision no longer has the capacity to inspire the support of a robust majority of U.S. voters. The renewal of dem- 
ocratic life must begin (but not end) with a focus on promoting new ideas and practices that cultivate the capacities of citizens within a democratic framework that is accountable, responsive, just and equitable in meeting the shared needs and aspirations of communities. The operation of democratic institutions within local communities where highly consequential decisions are made that tangibly and visibly impact citizens' everyday life can provide a grounded, compelling, and sorely needed site for broad democratic renewal.

In the next chapter of this book, Chapter 2, Melody C. Barnes and Thad M. Williamson propose "community wealth building" as a fresh policy paradigm capable of invigorating the practice of American democracy. Barnes and Williamson assert that community wealth building - defined by the local practice of inclusive participation, setting bold equity goals, economic innovation to broaden wealth ownership, and a holistic understanding of wealthprovides a pathway by which communities can forge strategies for visible, tangible progress on urgent community priorities, even in circumstances where the federal government is absent or even hostile to such efforts. The peculiar and painful history of the authors' hometown of Richmond, Virginia, which launched the nation's first municipal Office of Community Wealth Building in 2014, is invoked to show how community wealth building fits within a long arc of struggle against white supremacy and racism in the former capital of the Confederacy. But Barnes and Williamson go beyond previous uses of the "community wealth building" terminology to describe its potential as a model of not just local governance but American democracy as a whole - connecting local, state, and federal institutions. The ambitious goal of community wealth building, on this account, is to simultaneously address long-standing and debilitating structures of racial inequity, redress massive disparities in wealth and influence, reinvigorate robust local democratic practice, and reconfigure progressive federalism in a manner that provides both more resources and responsibility to devolved localities without sacrificing (indeed, while strengthening) needed federal protections of civil rights, labor law, environmental protections, and other required national standards.

The purpose of this book is to both present this conception of community wealth building, and to interrogate it from a variety of perspectives. In June 2019 , the contributors to this book, representing a variety of academic disciplines, gathered at the University of Richmond's Jepson School of Leadership Studies for a two-day discussion focused on community wealth building and the future of democracy. Contributors presented original papers relating to one or more of the themes raised in Barnes and Williamson's chapter; revised versions of those papers comprise the main body of the present book.

The proposed community wealth building paradigm necessarily touches on a range of topics and questions requiring greater scrutiny and critical reflection. The editors have grouped the remaining chapters into four main areas: race and 
American democracy (Part II); the political economy of community wealth building (Part III); political institutions and the possibility of reform (Part IV); and the practical challenges and possibilities of implementing community wealth building initiatives "on the ground" in American communities (Part V).

Following Chapter 2 by Barnes and Williamson, Part II addresses the ethical underpinnings of the community wealth building approach-in particular, its challenge to white supremacy in the U.S. In Chapter 3, Lawrie Balfour provides an in-depth discussion of reparations as a paradigm potentially operating parallel to the community wealth building proposal; she argues for an understanding of reparations not as a one-time fix for historical injustice but as a deepened commitment to recognizing the depth of those historical injustices and the need for ongoing corrective action that may include but should not be limited to specific bold steps. In Chapter 4, Corey D.B. Walker explicates the epistemological and ethical foundations of a robust community wealth building approach. Engaging with social theorists like Habermas and Foucault, Walker first argues that community wealth building is consonant with a commitment to generating local knowledge as an alternative to dominant knowledge paradigms; he goes on to argue that it is also consistent with the ethic of public action expressed by Martin Luther King's conception of the "beloved community." This extension of the Barnes/Williamson proposal is significant because it underscores the fact that a successful community wealth building program must do much more than simply appeal to or draw upon citizens' self-interest; instead, it must also call upon a vision of inclusive community sufficiently robust to motivate collective action and indeed collective solutions to enduring community challenges.

Part III relates community wealth building to broader issues of political economy, capitalism, and economic inclusion. In Chapter 5, Isabel Sawhill diagnoses American capitalism's long-term trend of generating ever-greater inequality while undermining economic security for the majority of Americans, a trend she blames largely on the ascendancy of neo-liberal, free-market policy orientations in Washington. Sawhill provides an incisive critique of the flaws in "market fundamentalism," then goes on to discuss several alternative political-economic paradigms that "reject the primacy of markets." Sawhill's analysis complements and extends the discussion of political economy paradigms in Barnes and Williamson's chapter on community wealth building.

In Chapter 6, Margaret Kohn turns to the very different context of the Italian cooperative movement to argue that community wealth building is not a novel proposal, but in fact is a paradigm that exists in practice, at scale, in an established democratic country. Cooperatives represent a way to broaden the ownership of wealth and stabilize particular communities; while different kinds of cooperatives can be found within all capitalist societies, only in a few cases do they occupy a substantial share of the market. Italy is one such case. Kohn's 
chapter details not only the significant scale and long-term staying power of Italian cooperatives, but also elaborates its supporting legal structures. This success holds important lessons for future efforts to expand and institutionalize community wealth building in the U.S.

In Chapter 7, Richard Dagger takes up the issue of housing policy and homelessness as both a critical issue facing local governments and as a fundamental test of civic inclusion. Drawing on a republican understanding of the free, equal, and independent citizen, Dagger argues that "housing-first" social policy approaches are required both to treat homeless individuals with appropriate civic respect and to model the type of inclusive community envisioned by community wealth building. The chapter is a helpful and timely example of how clear thinking about fundamental issues of citizenship can inform social policy in general and community wealth building agendas in particular.

Part IV examines the role of formal political institutions and recent trends in American electoral politics in extending or blocking robust democratic practice. Accountability is a core value of the community wealth building paradigm, but what exactly does accountability mean? In Chapter 8, Kenneth P. Ruscio explores this question in the context of contemporary debates about impeachment. His wary conclusion is that while the framers of the U.S. Constitution wisely anticipated the potential for abuse of executive power within a republican system, it remains far from clear that impeachment (or other tools) are in fact adequate to the problem of holding reckless elected officials accountable. This finding suggests that advocates of community wealth building - or other approaches that seek to hold public officials accountable not just for abuses of power, but for delivering clear progress on public problems - must develop or resuscitate new tools for holding government accountable. The question of the need for institutional innovations to improve democratic practice is taken up by J.S. Maloy in Chapter 9. Maloy argues that the emergent practice of ranked-choice voting in local and state elections is a marked improvement as a method of both registering the aggregated preferences of voters and allowing new political voices to emerge and be heard. Drawing on recent experiences in Ireland, Maloy goes on to argue that policy juries offer a promising method for soliciting both democratic voice and meaningful deliberation for polities facing challenging and complex issues. Because localities, states, and nations seeking to implement community wealth building agendas will regularly wrestle with complex and controversial proposals, Maloy's explication of these institutional alternatives is a welcome contribution.

Chapters 10 and 11 turn to voting, electoral behavior, and voting rights law in the U.S. In Chapter 10, Nicholas J.G. Winter demonstrates how the increased political polarization of American national politics is connected to stronger connections over the past generation between partisan identification and feelings about the racial, gender, and class groups associated with the 
parties. This means that the stakes of national political debates transcend simple policy disagreements because they are deeply entwined with race, gender, and other components of personal identity. This finding reinforces Barnes and Williamson's contention that national politics is largely stuck in stalemate and that there may be more promise for building consensus starting (but not ending) at more local levels of politics. In Chapter 11, Julian Maxwell Hayter traces the long roll-back of the Voting Rights Act, culminating in the Supreme Court's removal of its key enforcement mechanisms in Southern states with a long history of hostility and exclusion towards African American voters. He shows how this decision resulted from a long-term, determined campaign by right-wing opponents of the law. Hayter's deeply troubling narrative is a potent reminder that the ever-increasing diversity of the American population will not necessarily translate into a more diverse electorate if governments are permitted to implement rules that restrict rather than promote equitable voter participation.

Part V turns to the work of implementing community wealth building agendas in practice, within cities and communities as we find them. In the American context, any compelling progressive agenda must not only "talk about" race but highlight racial disparities as an urgent matter of justice. In Chapter 12, Ravi K. Perry argues that the language of "targeted universalism" gives politicians - especially African American politicians - a framework for highlighting racial inequities while building broad, inclusive progressive coalitions for change, including in majority-white cities. Perry draws on numerous examples to show how targeted universalism has been deployed in practice by relatively successful mayors. Because one requirement of community wealth building is strong political support from local political leadership, Perry's analysis helpfully shows how mayors and other local leaders can knit together robust political coalitions while speaking with integrity about ongoing injustices and exclusions that harm the least well off.

Chapters 13 and 14 examine practical efforts at community wealth building in the Richmond context. In Chapter 13, Risha R. Berry details the challenges faced by Richmond's Office of Community Wealth Building (OCWB) in confronting multiple layers of structural racism and building a strategy to help residents (primarily African American) in Richmond achieve economic stability and eventually build wealth. Berry describes the workforce development component of OCWB as well as related efforts to advocate for structural policy change and increased resources so as to tear down barriers to economic thriving faced by thousands of Richmond residents. Her chapter makes clear that a robust and successful community wealth building approach is not a matter of implementing one or two new programs or low-cost interventions, but requires concerted systemic change at multiple levels of program and policy, simultaneously. In Chapter 14, Barbara Brown Wilson and Meghan Z. Gough 
critically consider how two prominent public universities - the University of Virginia and Virginia Commonwealth University-act as anchor institutions for the cities of Charlottesville and Richmond, respectively. Wilson and Gough illustrate the challenge and possibility of aligning internal university imperatives (and associated politics) with community-wide need on a larger, more intentional scale than has historically been the case in either institution.

Finally, in Chapter 15, Corey D.B. Walker and Thad M. Williamson reflect on key themes emerging from this book, as well as the many remaining questions concerning the community wealth building paradigm to be addressed in future work. Both the editors and contributors regard this book as but one critical conversation point in the development of community wealth building as a robust paradigm for reviving and reconstructing American democracy, on (at last) genuinely inclusive and equitable terms. That conversation necessarily will involve further academic analysis, but perhaps even more importantly must draw on accumulating knowledge from implementation efforts in the field and the experiences and perspectives of practitioners and citizens. Community wealth building is less a prescription for specific policies than an orientation and process aimed at delivering bold, community-driven change - a process that must always begin and end with the agency of situated democratic citizens.

\section{REFERENCES}

King, Martin Luther, Jr. (1967), Where Do We Go from Here: Chaos or Community? New York: Harper \& Row.

Tocqueville, Alexis de (1835 [2004]), Democracy in America, translated by Arthur Goldhammer, New York: Library of America. 